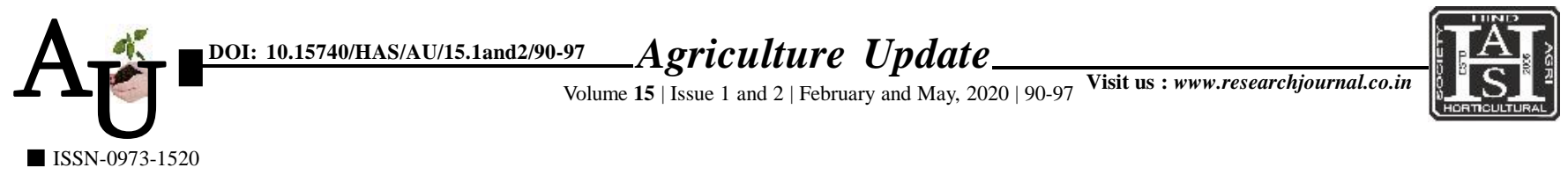

\title{
Research Article: Perception and adoption of soil health cards (SHCs) by the farmers in Kadapa district
}

\author{
N. Krishna Priya and B. Padmodaya
}

Article Chronicle: Received :

05.03.2020;

Revised :

14.04.2020;

Accepted :

22.04.2020

KeY Words :

SHC, Perception, Adoption, Non-

adoption, Constraints

SUMMARY : To understand the perception and adoption levels of soil health card the present study was undertaken in three mandals (Vallur C K Dinne and Vontimitta) comprising of 60 soil testing based beneficiaries in Kadapa district of Andhra Pradesh. The findings of study revealed that majority of the farmers had medium level of perception (67\%), followed by low (20\%) and high level of perception $(13 \%)$, respectively. Further results on the adoption levels of the selected respondents was that majority of the respondents (63.33\%) had not adopted recommended organic manures as per SHC results, recommended nitrogen as per SHC results 85 per cent of the respondents not adopted, recommended phosphorus as per SHC results 91.67 per cent not adopted, recommended potash as per SHC results 90 per cent of the respondents not adopted, recommended micro nutrients as per SHC results 80 per cent of the respondents not adopted and recommended gypsum/lime as per SHC results 96.67 per cent of the respondents not adopted. Further results on the constraints, farmers feel that fertilizer dose is not sufficient if applied as per SHC result ranks first followed by difficult to understand and follow the recommended doses ranks second etc. The suggestion offered for the increase of soil health card adoption by the farmers were method of calculating the fertilizer dose on the basis of nutrient status of the soil should be given on SHC, training should be given on soil sample collection procedure and also its importance and contact number should be given in the SHC. With respect to the results on the reasons for non-adoption of soil health cards as perceived by the mandal agricultural officers is that not receiving timely soil health card to farmers ranks first followed by lack of awareness on the importance of soil testing ranks second and applying over doses of fertilizers by comparing with other farmers in the village ranks third etc.

How to cite this article : Priya, N. Krishna and Padmodaya, B. (2020). Perception and adoption of soil health cards (SHCs) by the farmers in Kadapa district. Agric. Update, 15(1 and 2): 90-97; DOI : 10.15740/HAS/AU/ 15.1and2/90-97. Copyright@ 2020: Hind Agri-Horticultural Society.

Author for correspondence :

N. Krishna Priya

Krishi Vigyan Kendra, Utukur, Kadapa (A.P.) India

Email: Priyarambabu143 @ gmail.com

See end of the article for authors' affiliations 